\title{
Los principios procesales de las acciones colectivas: un estudio comparado en Europa y Latinoamérica***
}

\section{The Procedural Principles of Collective Actions: A Comparative Study in Europe and Latin America}

\section{RESUMEN}

En este trabajo se investigan desde el derecho comparado, en el ámbito del constitucionalismo contemporáneo y del derecho convencional, los principios procesales de las acciones colectivas que han sido adoptados por los sistemas jurídicos de algunos países de Europa, como España, Francia y Alemania, y de Latinoamérica, como México, Brasil y Colombia, a fin de conocer sus similitudes y diferencias, que permita, por una parte, acrecentar la cultura de los operadores jurídicos, y por la otra, facilitar el derecho humano de acceso a la justicia. Tomamos como base de esta investigación la teoría constitucional, la teoría del derecho constitucional, la teoría del derecho procesal constitucional, la teoría general del proceso y la teoría de los derechos fundamentales. Debido a ello, nos vimos en la necesidad de acudir a la doctrina y a la legislación de cada uno de los países mencionados, en el entendido de que si, de suyo, cualquier estudio que se realiza al amparo de una teoría es en sí mismo complejo, un estudio basado en cinco teorías, evidentemente, tiene un grado de complejidad aún mayor.

Doctor en Derecho Penal. Profesor investigador del Centro de Investigaciones en Ciencias Jurídicas, Justicia Penal y Seguridad Pública de la Facultad de Derecho de la Universidad Autónoma del Estado de México. Profesor con reconocimiento con perfil deseable para profesores de tiempo completo (PRODEP-SEP), integrante del Sistema Nacional de Investigadores (SNI), Nivel 1. Líder del Cuerpo Académico "Estudios en Derecho Social, Procesos Sociales y Políticos", en Consolidación. Responsable de la Red Internacional "Estudios Iberoamericanos en los Procesos Democráticos en el EstadoConstitucional”.Contacto: rodolfoelizaldecas@yahoo.com.mx ORCID ID: 0000-0001-8680-3581. Maestro en Derecho con área terminal en Justicia Constitucional por la Facultad de Derecho de la Universidad Autónoma del Estado de México; maestrante de la Maestría en Derecho por la Facultad de Derecho de la Universidad Nacional Autónoma de México. Contacto: fran_mejia84@hotmail.com oRCID ID: 0000-0003-2908-0588

Recibido el 9 de mayo de 2019, aprobado el 15 de septiembre de 2021.

Para citar el artículo: Elizalde Castañeda, R. R. y Cisneros Mejía, F. A. Los principios procesales de las acciones colectivas: un estudio comparado en Europa y Latinoamérica. En Revista Derecho del Estado, Universidad Externado de Colombia. N. . 51, enero-abril de 2022, 73-101. DOI: https://doi.org/10.18601/01229893.n51.03 
PALABRAS CLAVE

Acciones colectivas, principios procesales, derecho constitucional, derecho procesal constitucional, derechos sociales, derecho humano de acceso a la justicia, derechos fundamentales.

\section{ABSTRACT}

This work investigates from comparative law, in the field of contemporary constitutionalism and conventional law, the procedural principles of collective actions that have been adopted by the legal systems of some European countries, such as Spain, France and Germany, and Latin America, such as Mexico, Brazil and Colombia, in order to know their similarities and differences that allow to increase the culture of legal operators, on the one hand, and, on the other, to facilitate the human right of access to justice. We take as the basis of this research, the constitutional theory, the theory of constitutional law, the theory of constitutional procedural law, the general theory of the process and the theory of fundamental rights. Therefore, we found ourselves in the need to resort to the doctrine and legislation of each of the countries mentioned, in the understanding that, if in itself, any study that is carried out under the protection of a theory is, in itself same complex; Now a study based on five theories obviously has an even higher degree of complexity.

\section{KEYWORDS}

Collective actions, procedural principles, constitutional law, constitutional procedural law, social rights, human right of access to justice, fundamental rights.

SUMARIO

Introducción. 1. Marco teórico-conceptual de las acciones colectivas y los principios procesales. 1.1. Las acciones colectivas. 1.2. Los principios procesales. 2. Los principios procesales de las acciones colectivas en Europa y Latinoamérica. 2.1. Europa. 2.1.1. España. 2.1.2. Alemania. 2.1.3. Francia. 2.2. Latinoamérica. 2.2.1. Brasil. 2.2.2. México. 2.2.3. Colombia. 2.2.4. Similitudes y diferencias. A manera de conclusiones. Referencias.

\section{INTRODUCCIÓN}

Este trabajo es un estudio, desde el derecho comparado, sobre los principios procesales de las acciones colectivas en el constitucionalismo contemporáneo europeo (España, Francia y Alemania) y latinoamericano (Brasil, México y 
Colombia), y desde el derecho convencional, con la finalidad de conocer sus similitudes y diferencias.

Como bien lo señala el maestro Gregório Assagra de Almeida, los principios, sin lugar a dudas, asumen una función nuclear en cualquier ámbito del derecho procesal, por lo que el caso del derecho procesal colectivo no es la excepción. Y ello, sobre todo, al momento de abordar su eficacia, pues sus "normas procesales no están bien delineadas y sedimentadas"1.

Se trata de un tema inédito, pues al revisar el estado del arte no encontramos algo parecido; lo más cercano a la tutela colectiva son estudios generales sobre el tema de las acciones colectivas y, en todo caso, cuestiones aisladas sobre alguno de los principios, como la legitimación plural, la cosa juzgada, la ejecución de sentencia, el derecho de defensa, el principio de audiencia, el debido proceso. Por esta razón, tuvimos que analizar los referidos principios, lo cual no fue una tarea nada fácil. Además, se trata de un tema novedoso y con trascendencia social y jurídica, pues la actividad desplegada durante el proceso de comparación jurídica nos permitió acudir a las legislaciones aplicables de los países en estudio, y ello, consideramos, igualmente, ayudará a acrecentar la cultura de los operadores jurídicos para llevar a cabo la tutela de los derechos sociales y de esa manera facilitar el derecho humano de acceso a la justicia.

El objetivo general fue investigar y analizar en la doctrina y las legislaciones contemporáneas de los países mencionados, y en el derecho convencional, los principios procesales que les han permitido tutelar las acciones colectivas con la idea de conocer sus similitudes y diferencias.

Las preguntas de investigación que orientaron este trabajo fueron: ¿cuáles son los principios procesales que sustentan los derechos colectivos en los sistemas jurídicos de algunos países de Europa, como Alemania, España y Francia, así como en algunos países de América Latina, como Brasil, México y Colombia? ¿Cuáles son las similitudes y diferencias de los principios procesales para la tutela de los derechos colectivos entre los países mencionados?

El marco teórico que sirvió de referencia se sustentó en la teoría de la constitución, el derecho constitucional, la teoría del derecho procesal constitucional, la teoría general del proceso y la teoría de los derechos fundamentales.

Asimismo, utilizamos los métodos deductivo, dialéctico, analítico, sintético, jurídico, documental y comparativo.

1 Assagra de Almeida, G. Artículo 39. En Gidi, A. y Ferrer Mac-Gregor, E. (coords.), Código Modelo de Procesos Colectivos. Un diálogo iberoamericano. Comentarios artículo por artículo. México: Porrúa-unam, 2008, 394. 
1. MARCO TEÓRICO CONCEPTUAL DE LAS ACCIONES COLECTIVAS Y LOS PRINCIPIOS PROCESALES

\subsection{Las acciones colectivas}

Los derechos sociales empezaron a gestarse a finales del siglo XIX con las reclamaciones laborales que se iniciaban en plena Revolución Industrial, tanto en algunos países de Europa como en América. En opinión de López Daza, en los derechos humanos económicos, sociales y culturales, ubicados cronológicamente en la segunda generación, como salud, vivienda, educación, seguridad social, sistema pensional, derecho de asociación y derecho de huelga, se involucra al Estado como principal responsable de su prestación. Así es como surgen las acciones colectivas tendientes a protegerlos ${ }^{2}$.

Para entender y comprender mejor las acciones colectivas es necesario referirnos a los intereses que tutelan; es por ello que abordaremos los derechos colectivos en sentido estricto, los derechos difusos y los derechos individuales homogéneos. Lo anterior en virtud de que tanto en las legislaciones occidentales como en la doctrina se atribuye una connotación genérica a los "derechos colectivos", siendo sus especies los "derechos difusos y colectivos (en sentido estricto)" y los derechos individuales homogéneos, también denominados derechos de incidencia colectiva. Sobre la base de esta clasificación procederemos a explicar cada uno de esos derechos.

Así pues, siguiendo en este tema a Gidi, el "derecho difuso" es aquel que pertenece a la comunidad como un todo, no a los miembros individuales del grupo; asimismo, el citado autor señala que este tipo de derechos son transindividuales e indivisibles, pertenecen a un grupo de gente no identificable, sin vínculos previos, que solamente está relacionada entre sí por un acontecimiento específico ${ }^{3}$. A manera de ejemplo, Gidi señala que estos derechos se encuentran en los campos de protección del medio ambiente y del consumidor.

2 López DAzA, G. A. Los derechos sociales en Alemania, España, Italia y Francia. En Criterio Jurídico, Santiago de Cali. Vol. 12, n. ${ }^{\circ}$ 1, 2012, 1. Véase, también, FAuth, G. y Villavicencio Calzadilla, M. P. Una reflexión sobre los "nuevos" derechos. Perspectivas y desafios en el siglo XXI. En Revista de la Facultad de Derecho, PUCP. N. . 70, 2013, 279-289. "[L]o que se interpreta como nuevo en el derecho es la 'desprivatización' de intereses, eso significa que se introduce en una configuración de intereses y derechos difusos y colectivos" (ibíd., 280); lo que, en opinión de las autoras, desconecta al derecho de los individualismos sustentados por la Revolución Francesa de 1789. Cfr., asimismo, Silvera de PAULI, M. Algunas peculiaridades del derecho al medio ambiente en la Teoría de los derechos humanos. Tesis, Universidad de Burgos, 2014; Armenta-Deu, T. Acciones colectivas: reconocimiento, cosa juzgada y ejecución. Madrid: Marcial Pons, 2013, 11-34.

3 GIDI, A. Las acciones colectivas y la tutela de los derechos difusos, colectivos e individuales en Brasil. Un modelo para países de derecho civil. Lucio Cabrera Acevedo (trad.). México: unAm-IIJ, 2004, 57. También, véase Gómez RodríGuEz, J. M. La contribución de las acciones colectivas al desarrollo regional desde la perspectiva del derecho social. En Cuestiones Constitucionales. Revista Mexicana de Derecho Constitucional. N. . $30,2014,79$. 
Respecto al "derecho colectivo", el mismo autor lo define como transindividual y divisible. Este derecho difiere del derecho difuso pues, en lugar de que el grupo esté constituido por un número indefinido de personas ligadas tan solo por hechos circunstanciales (vivir en el mismo vecindario, comprar el mismo producto, ver el mismo programa de televisión, etc.), los miembros del grupo en el caso de los derechos colectivos están ligados unos a otros, o a la contraparte, por una relación jurídica previa ${ }^{4}$.

Por lo que hace a los "derechos individuales homogéneos", Gidi destaca que son los mismos derechos individuales que tradicionalmente han sido conocidos en el sistema de derecho civil como "derechos subjetivos". El nuevo concepto de derechos individuales homogéneos solo refleja la creación de un nuevo instrumento procesal para el tratamiento unitario de los derechos individuales relacionados entre sí en una sola acción: la acción colectiva por daños individuales ${ }^{5}$.

De lo anterior se desprende que los derechos colectivos, en sentido amplio, se clasifican en derechos difusos, derechos colectivos (stricto sensu) y los derechos individuales de incidencia colectiva. Los primeros comparten la característica de pertenecer a un grupo o colectividad como un todo, y por ello son transindividuales e indivisibles, en virtud de que los intereses de los miembros del grupo están estrechamente relacionados; mientras que, en el último grupo, la principal característica es que son derechos individuales y divisibles cuyos titulares son individuos agrupados con base en circunstancias de hechos comunes. Estas circunstancias de derechos comunes hace que se les califique de homogéneos.

\subsection{Los principios procesales}

Los principios procesales asumen una función esencial en las acciones colectivas, en razón de que son criterios que orientan e inspiran el eficaz desenvolvimiento de su propio proceso. Lo anterior se desprende de las palabras de Vázquez Sotelo cuando, en lo particular, asevera que "[1]os principios procesales son los criterios constitutivos o informadores que inspiran, configuran y dominan una regulación procesal. Suelen responder a los valores que el legislador desea proteger en una determinada época y por eso tienen una significación axiológica. Responden también a exigencias artísticas o técnicas para su mayor eficacia al servicio de los fines que se requieren alcanzar"6.

4 GIDI, A. Las acciones colectivas y la tutela de los derechos difusos, cit., 59.

5 Ibíd., 61.

6 VÁzquez Sotelo, J. L. Los principios del proceso penal: legalidad, oportunidad y condena pactada. En Picó I Junoy, J. (coord.), Principios y garantías procesales. Barcelona: Bosch, 2013, 457. 
Por su parte, Borthwick alude a varios autores que aportan conceptos diferentes sobre el tema de los principios procesales: así, W. Millar sostiene que dichos principios constituyen las generalizaciones o conceptos fundamentales que consciente o inconscientemente dan forma y carácter a los sistemas procesales ${ }^{7}$. A su turno, Bacre los define como "ideas fundamentales referidas a la estructuración de un proceso, que le dan su base"8. Para Jorge W. Peyrano, son construcciones normativas jurídicas de índole subsidiaria, producto de la más cuidadosa decantación técnico-sistemática de las normas que regulan un proceso civil dado, no excluyentes, en general, de sus antítesis lógicas o de las consecuencias de estas, que contribuyen a integrar los vacíos que presenta la regulación normativa donde ven la luz, pero cuya primera misión es la de servir de faro para que el intérprete, sea juez, legislador o tratadista, no equivoque el camino y olvide que toda solución proccidental propuesta debe armonizar con ellas, so pena de introducir la incoherencia allí donde resulta nefasta, es decir, en el ámbito del proceso9. Mientras que Clemente Díaz los denomina "principios generales del derecho procesal", y los describe como aquellos presupuestos políticos que determinan la existencia funcional de un ordenamiento procesal cualquiera", asegurando que concretan y mediatizan las garantías constitucionales del derecho procesal y en donde, en cada uno de aquellos, se puede encontrar un entroncamiento directo con una norma constitucional ${ }^{10}$.

Profundizando sobre el tema de los "principios", para tener una idea más orientada al respecto, resulta conveniente destacar la distinción entre "los principios" y "las reglas", haciendo referencia a las posturas de Ronald Dworkin, Gustavo Zagrebelsky y Robert Alexy. Para el primero de ellos, las reglas se aplican de modo todo o nada, en el sentido de que, si se cumple el supuesto de hecho de una regla, o bien la regla es válida, y se acepta la consecuencia normativa, o bien la regla no se considera válida. En el caso de colisión entre reglas, una de ellas debe considerarse válida. Los principios, por el contrario, no determinan absolutamente la decisión, pues solamente contienen fundamentos que deben conjugarse con otros fundamentos provenientes de otros principios. De ahí que los principios, al contrario de las reglas, poseen una dimensión de peso; por lo que, en caso de colisión entre los principios, el principio con un peso relativo mayor se superpone al otro sin que este pierda su valide $\mathrm{z}^{11}$.

7 Borthwick, A. E. Principios procesales, Argentina, mave, 2003, 17. Véase, también, Armienta Calderón, G. M. Teoría general del proceso. Principios, instituciones y categorías procesales. México: Porrúa, 2003, 120; cfr. Ávila, H. Teoría de los principios. Laura Criado Sánchez (trad.). España: Marcial Pons, 2011, 34-35.

8 Borthwick, A. E. Principios procesales, cit., 18

9 Ibíd., 19.

10 Ibíd.

11 Ávila, H. Teoría de los principios, cit. 34-35. 
Al respecto, Zagrebelsky asegura que el derecho actual está compuesto por reglas y principios, identificando a las primeras como las normas legislativas, y a los segundos como normas constitucionales; en ese sentido, hace una distinción más simple entre reglas y principios al decir que no es otra cosa que la diferencia entre la ley y la Constitución ${ }^{12}$. Este mismo autor agrega que los principios son producto de tradiciones históricas e incluso permiten cierto significado de valor. La importancia que se destaca de esta distinción es que en la aplicación de las reglas solo se hace uso de un silogismo jurídico, mientras que los principios, al momento de ser aplicados, exigen una reacción por parte del intérprete, le imponen una tarea de ponderación ${ }^{13}$.

Discurriendo en la misma línea, Suárez Romero sostiene que las vías de conexión entre el derecho y la moral son los principios, los cuales, al ser de naturaleza moral, reclaman del juez o intérprete una ponderación, por lo que su validez jurídica no va a depender de su plausibilidad moral, sino más bien de una efectiva vigencia ${ }^{14}$.

En este tema seguiremos a Alexy, quien en su Teoría de los derechos fundamentales profundiza en la distinción entre reglas y principios, pues, en sus propias palabras, esta es la más importante de las distinciones para su Teoría de los derechos fundamentales ${ }^{15}$; y, agrega,

... constituye la base de la fundamentación iusfundamental y es una clave para la solución de problemas centrales de la dogmática de los derechos fundamentales. Sin ella, no puede existir una teoría adecuada de los límites, ni una teoría satisfactoria de la colisión[,] y tampoco una teoría suficiente acerca del papel que juegan los derechos fundamentales en el sistema jurídico. Es un elemento básico no sólo de la dogmática de los derechos de libertad e igualdad, sino también de los derechos a protección, organización y procedimiento y a prestaciones en sentido estricto. [...] Por todo esto, la distinción entre reglas y principios es uno de los pilares fundamentales del edificio de la teoría de los derechos fundamentales ${ }^{16}$.

Por ello, continúa exponiendo nuestro autor, "[n]o pocas veces, las normas iusfundamentales son llamadas "principios" ". Sin embargo, otras veces se habla también de valores, de objetivos, de fórmulas abreviadas, o de reglas de carga de la prueba. Lo que en palabras de Alexy no está muy claro, por lo

12 García Pino, G. Gustavo Zagrebelsky: en busca de la razón en el derecho. En Revista de Derecho Público. Vol. 80, 1. ${ }^{\mathrm{er}}$ semestre, 2014, 53-84.

13 SuÁrez Romero, M. A. Ley, principios jurídicos y derechos fundamentales en el actuar de los jueces y legisladores. Una propuesta positivista ante la templanza del constitucionalismo. En Derechos y Libertades, unAm. Época II, n. ${ }^{\circ}$ 36, 2017, 237.

14 Ibíd., 238.

15 Alexy, R. Teoría de los derechos fundamentales. Madrid: Centro de Estudios Constitucionales, $1993,81$.

16 Ibíd., 81-82.

17 Ibíd., 82. 
que insiste en su distinción cuando afirma que las mismas normas se dividen en reglas y principios, entre los cuales existe una diferencia cualitativa.

Alexy sostiene también que un problema entre reglas se soluciona de dos formas: una, introduciendo una cláusula de excepción para eliminar esa confrontación; otra, declarando inválida una de las reglas.

Otras de las reglas que han surgido para la solución de esa problemática son la regla "Lex posterior derogat legi priori" y la regla "Lex specialis derogat legi generali". Otro criterio consiste en proceder de acuerdo a la importancia de las reglas en conflicto, esto es, la ley más importante está sobre la menos importante.

Ahora bien, aquí surge una cuestión: ¿cómo se solucionan los problemas entre los principios, cuando estos se contradicen? Es importante tomar en cuenta que, cuando dos principios entran en colisión, significa que un principio dice que algo está prohibido y otro refiere que eso mismo está permitido. Pero, más bien, lo que sucede es que, bajo ciertas circunstancias, uno de los principios precede al otro. "Esto es lo que se quiere decir cuando se afirma que en los casos concretos los principios tienen diferente peso y que prima el principio con mayor peso [...] [L]a colisión de principios -como sólo pueden entrar en colisión principios válidos- tiene lugar más allá de la dimensión de validez, en la dimensión de peso" ${ }^{18}$. Estamos frente a lo que el jurista alemán identifica como la "Ley de colisión", que es otro "de los fundamentos de la teoría de los principios" ${ }^{19}$. En otras palabras, ¿bajo cuáles condiciones cuál principio tiene precedencia? Y, ¿cuál debe ceder? En este contexto, el tribunal se sirve de la muy difundida metáfora del peso. Pero, el tema del peso no tiene que ver con el tema de la cuantificación, sino con el tipo de intereses o derechos que están en juego.

Otro aspecto que cabe destacar de la teoría entre reglas y principios es el carácter prima facie, que significa que

... [1]os principios ordenan que algo debe ser realizado en la mayor medida posible, teniendo en cuenta las posibilidades jurídicas y fácticas. Por lo tanto, no contienen mandatos definitivos sino solo prima facie. Del hecho de que un principio valga para un caso no se infiere que lo que el principio exige para este caso valga como resultado definitivo. Los principios presentan razones que pueden ser desplazadas por otras razones opuestas ${ }^{20}$.

Humberto Ávila ratifica esta postura cuando sostiene que los principios jurídicos solo consisten en una especie de normas jurídicas por medio de las que se establecen deberes de optimización aplicables en varios grados, según las

18 Ibíd.

19 Ibíd., 94-95.

20 Ibíd., 99. 
posibilidades normativas y fácticas. En el caso de colisión entre principios, sostiene que la solución no se resuelve con la determinación inmediata de la prevalencia de un principio sobre otro, sino que se establece en función de la ponderación entre los principios opuestos, en función de la cual uno de ellos, en determinadas circunstancias, prevalece. Por lo tanto, como ya se mencionó supra, los principios, al contrario de las reglas, poseen tan solo una dimensión de peso y no determinan las consecuencias normativas de forma directa ${ }^{21}$.

A partir de lo anterior, podemos hablar de los principios procesales rectores de las acciones colectivas, los cuales, en la medida en que se extraen de un determinado contexto normativo, van a expresar el sentido y el alcance de la tutela de los intereses, ya sean colectivos (stricto sensu), difusos u homogéneos.

\section{LOS PRINCIPIOS PROCESALES DE LAS ACCIONES COLECTIVAS EN EUROPA Y LATINOAMÉRICA}

\subsection{Europa}

\subsubsection{España}

En España, una acción de tutela de intereses colectivos se manifiesta en la Ley de Enjuiciamiento Civil de $2000^{[22]}$, que en el artículo 11 reconoce la legitimación de las asociaciones de consumidores y usuarios legalmente constituidas, para defender en juicio los derechos e intereses de sus asociados y los de la asociación, así como los intereses generales de los consumidores y usuarios:

Artículo 11. Legitimación para la defensa de derechos e intereses de consumidores y usuarios.

1. Sin perjuicio de la legitimación individual de los perjudicados, las asociaciones de consumidores y usuarios legalmente constituidas estarán legitimadas para defender en juicio los derechos e intereses de sus asociados y los de la asociación, así como los intereses generales de los consumidores y usuarios.

2. Cuando los perjudicados por un hecho dañoso sean un grupo de consumidores o usuarios cuyos componentes estén perfectamente determinados o sean fácilmente determinables, la legitimación para pretender la tutela de esos intereses colectivos corresponde a las asociaciones de consumidores y usuarios, a las entidades legalmente constituidas que tengan por objeto la defensa o protección de éstos, así como a los propios grupos de afectados.

21 Ávila, H. Teoría de los principios, cit., 36.

22 Ley de Enjuiciamiento Civil de 2000. Boletín Oficial del Estado. 
3. Cuando los perjudicados por un hecho dañoso sean una pluralidad de consumidores o usuarios indeterminada o de difícil determinación, la legitimación para demandar en juicio la defensa de estos intereses difusos corresponderá exclusivamente a las asociaciones de consumidores y usuarios que, conforme a la Ley, sean representativas.

4. Las entidades habilitadas a las que se refiere el artículo 6.1.8 estarán legitimadas para el ejercicio de la acción de cesación para la defensa de los intereses colectivos y de los intereses difusos de los consumidores y usuarios.

Los Jueces y Tribunales aceptarán dicha lista como prueba de la capacidad de la entidad habilitada para ser parte, sin perjuicio de examinar si la finalidad de la misma y los intereses afectados legitiman el ejercicio de la acción.

5. El Ministerio Fiscal estará legitimado para ejercitar cualquier acción en defensa de los intereses de los consumidores y usuarios.

Rosales Sánchez señala que el precepto legal en cita distingue entre intereses colectivos e intereses difusos con apoyo en el grado de determinación de los sujetos afectados: si los sujetos afectados están perfectamente determinados o son fácilmente determinables, sus intereses son calificados como colectivos; si los perjudicados son una pluralidad de personas indeterminada o de difícil determinación sus intereses son considerados difusos ${ }^{23}$.

En ese mismo sentido, Barajas Villa indica que son varias las personas y organizaciones a quienes se les reconoce legitimación en el ordenamiento español: es así como encontramos a los perjudicados en lo individual, las asociaciones de consumidores y usuarios, las entidades legalmente constituidas, el ministerio fiscal y los grupos afectados determinados o fácilmente determinables. Esta legitimación conduce a dos supuestos distintos: la legitimación para la defensa de los intereses colectivos y difusos y la legitimación colectiva para reclamar los daños y perjuicios que se hayan ocasionado a los consumidores y usuarios considerados individualmente ${ }^{24}$.

Por su parte, Corominas Bach ${ }^{25}$, de conformidad con el modelo español, señala los siguientes principios:

23 Cfr. Rosales SÁnchez, J. J. Introducción a las acciones colectivas. En CASTILlo GonZÁlez, L. y Murillo Morales, J. (coords.), Acciones colectivas. Reflexiones desde la judicatura. México: Instituto de la Judicatura Federal, Escuela Judicial, 2013, 26.

24 Cfr. Barajas Villa, M. La construcción jurisprudencial de la tutela efectiva de los derechos humanos, a través del método del derecho comparado: clave del éxito de las acciones colectivas en México. En Castillo González, L. y Murillo Morales, J. (coords.), Acciones colectivas, cit., 107.

25 COROMINAS BACH, S. La legitimación activa en las acciones colectivas. Tesis doctoral, Universidad de Girona, 2015, 37. 
1. Principio constitucional económico. Está regulado en el artículo 51 de la Constitución española ${ }^{26}$ y se traduce en que los poderes públicos desplieguen una protección eficaz de los intereses pertenecientes a un colectivo, garantizando la defensa de consumidores y usuarios.

2. Principio pro actione. Este derecho, concretamente, se ha materializado en la práctica de los tribunales en una interpretación de la normativa procesal a favor del inicio del proceso. Este principio implica que deben evitarse los denominados "formalismos enervantes", entre otros posibles impedimentos en el acceso a la jurisdicción de los intereses apuntados ${ }^{27}$.

3. Principio de la preeminencia del derecho en una sociedad democrática. Respecto a la obligación por parte del Estado de tutelar el derecho u obligación reconocidos en su ordenamiento jurídico, el grado de acceso procurado por la legislación nacional ha de ser suficiente para asegurar al individuo el derecho a un tribunal. En este sentido, la afectación de un derecho o interés protegido por el ordenamiento jurídico no podrá quedar sin la tutela judicial respectiva ${ }^{28}$.

4. Principio de estabilidad de las resoluciones judiciales y de seguridad jurídica. Este derecho se encuentra regulado en el artículo 214 de la Ley de Enjuiciamiento Civil y en el artículo 267 de la Ley Orgánica del Poder Judicial, donde se hace hincapié en que las resoluciones dictadas y que hayan alcanzado firmeza en los procesos colectivos no deberán ser modificadas ni alteradas por ningún motivo, salvo aclarar o rectificar aquellos errores materiales de los que adolezca, sin variar su sentido.

Es importante mencionar que la sentencia ha de determinar si los efectos de la cosa juzgada han de extenderse a los consumidores que no hayan sido parte ni comparecido en el proceso, y que, en caso de no efectuarse el citado pronunciamiento, la cosa juzgada no se limita a los que hayan sido parte en el proceso, sino que alcanza a todos los perjudicados en quienes se concrete el ejercicio de la acción. Es de destacar el modelo opt-in o inclusivo previsto en los ordenamientos jurídicos europeos occidentales, ya que únicamente se verán afectados por la sentencia que ponga fin al proceso colectivo los miembros que hayan manifestado su voluntad de ser parte en el mismo de modo expreso ${ }^{29}$.

5. Principios de oficialidad y dispositivo. En los procesos colectivos debe comprobarse el cumplimiento de requisitos objetivos de legitimación de la parte actora. Aunque, tratándose de la defensa de las acciones colectivas,

26 Constitución española de 1978.

27 Corominas Bach, S. La legitimación activa, cit., 90.

28 Tribunal Europeo de Derechos Humanos. Caso F.E. contra Francia. Sentencia de 30 octubre 1998. Repertorio de sentencias y decisiones 1998-vIII, pg.- 3349, ap. 44, y Caso Yagtzilar y otros contra Grecia, Sentencia 41727/1998, a p. 23, CEDH 2001-XII. Citado por COROMINAS BACH, S. La legitimación activa, cit., 96.

29 Corominas B ACH, S. La legitimación activa, cit., 148-149. 
el Tribunal Supremo español, en una sentencia del 17 de junio de 2010, ha ido más allá, al disponer que la cosa juzgada no debe ser un obstáculo cuando se trate de proteger a los consumidores. Por lo que será en la sentencia donde se deberá aclarar si la situación que se resolvió alcanza a los consumidores que no fueron parte del proceso $^{30}$.

6. Principio de indemnización real del daño. Busca una indemnización total del mismo ante una sentencia favorable. En fase de ejecución se procederá a determinar la cuantía indemnizatoria siguiendo lo previsto en el artículo 519 de la Ley de Enjuiciamiento Civil ${ }^{31}$.

7. Principio de "quien pierde, paga". Se refiere a que la parte que obtenga el sentido desfavorable de la sentencia debe cubrir las costas procesales ${ }^{32}$.

\subsubsection{Alemania}

Los derechos sociales en Alemania fueron consagrados en la Constitución de Weimar ${ }^{33}$; sin embargo, en la Constitución Federal vigente ${ }^{34}$ se nota su ausencia, aunque sí se encuentran regulados en la legislación ordinaria ${ }^{35}$, si bien esta no contempla una regulación específica en materia de acciones colectivas. Harald Koch, profesor de la universidad de Hamburgo, señala que en el procedimiento alemán, el mecanismo de defensa de los derechos colectivos no es desconocido, pero está limitado a ciertos tipos de resarcimientos y para ciertos representantes con legitimación pública ${ }^{36}$.

En ese sentido, el derecho alemán ha permitido a ciertas asociaciones concurrir ante los tribunales en nombre propio, siendo de resaltar que tales autorizaciones se limitan a determinadas materias y suponen la previsión explícita de la ley ${ }^{37}$. Por tanto, a las asociaciones se les permite solicitar de los tribunales una resolución únicamente en los casos previsto por la ley. Sin embargo, las acciones concedidas por tales disposiciones siempre son

$30 \quad$ Ibíd., 244.

31 Ibíd., 272 ss.

32 Ibíd., 222 ss.

33 López Oliva, J. O. La Constitución de Weimar y los derechos sociales. La influencia en el contexto constitucional y legal colombiano a la luz de los derechos sociales asistenciales a la seguridad social en salud. En Novum Jus. Vol. 4, n. ${ }^{\circ}$ 1, 2010, 25-28.

34 Ley Fundamental de la República Federal de Alemania, 2010.

35 Ibíd., 27-28.

36 Косн H. Procesos colectivos. La tutela de los derechos difusos, colectivos e individuales en una perspectiva comparada. En GIDI, A. y Ferrer MAC-GREGOR, E. (coords.), Procesos colectivos. La tutela de los derechos difusos, colectivos e individuales en una perspectiva comparada. 2. ${ }^{a}$ ed. México: Porrúa, 2004, 242; véase, también, Armenta Deu, T. Acciones colectivas: reconocimiento, cosa juzgada y ejecución, cit., 16-17.

37 Hernández Martínez, M. D. P. Mecanismos de tutela de los intereses difusos y colectivos. México: UNAM, 1997, 139. 
consideradas como acciones ordinarias civiles, por lo que consecuentemente conocen de ellas los tribunales civiles.

$\mathrm{Al}$ respecto, Barajas Villa señala que una tutela de los derechos colectivos en Alemania se presenta en la Ley de Competencia Desleal, la cual concede legitimación a los operadores comerciales directamente lesionados en sus propios derechos o por cualquier sujeto que actúe en el mismo o en un análogo sector del comercio, así como por asociaciones que defiendan los intereses del comercio y los consumidores ${ }^{38}$.

Así pues, en el procedimiento civil alemán se han reconocido las acciones de clase (Verbandsklage) para las asociaciones registradas, quienes tienen la autoridad para demandar en el interés de sus miembros o en nombre propio: así por ejemplo, una asociación cervecera puede presentar una demanda en contra de los almacenes para retornar sus botellas de acuerdo con el esquema de depósito; y una asociación de abogados puede presentar la solicitud de una orden judicial para prevenir el desarrollo de una práctica judicial no autorizada en el interés de sus miembros ${ }^{39}$.

A partir de lo anterior, podemos entrar al terreno de los principios de las acciones colectivas, pues en el sistema jurídico alemán impera el "principio de la libre concurrencia", en razón de que el supuesto en el cual se ejercita más la acción es el que prevé la ley sobre concurrencia ilícita. Aquí la Corte Constitucional alemana reconoce que dicha ley no solo implicaba defender el principio de la libre concurrencia contra las prácticas desleales, sino también a proteger a los consumidores en general ${ }^{40}$.

Asimismo, el derecho alemán requiere como prerrequisito el "principio de legitimación activa", para que las partes presenten sus razones para demandar o defenderse.

\subsubsection{Francia}

En el caso particular de Francia, los antecedentes de los derechos sociales datan de las constituciones de 1793, 1848 y 1946 y llegan a la actual de $1958^{[41]}$. Pero, hasta el año 2014 no existía ninguna acción comparable con las acciones colectivas; sin embargo, se establecían diversos mecanismos en los que se manifestaba una defensa pública del medio ambiente, así como una acción de los consumidores asociados contra las cláusulas de los contratos privados por adhesión.

38 BaRAJAS VILLA, M. La construcción jurisprudencial de la tutela efectiva de los derechos humanos, a través del método del derecho comparado: clave del éxito de las acciones colectivas en México. En Castillo González, L. y Murillo Morales, J. (coords.), Acciones Colectivas, cit., 106.

39 Косн, H. Procesos colectivos. La tutela de los derechos difusos, colectivos e individuales en una perspectiva comparada, cit., 242.

40 Ibíd.

41 Cfr. López Daza, G. A. Los derechos sociales en Alemania, cit., 37. 
De tal suerte, la ley de 1901 relativa al contrato de asociaciones prevé en sus artículos 5 y 6 que las asociaciones régulièrement déclarée pueden, sin ninguna autorización especial, comparecer a juicio, adquirir a título oneroso, poseer o administrar bienes. Por su parte, la diversa ley de 1920 consagra la norma en materia de tutela jurisdiccional de los sindicatos profesionales ${ }^{42}$. Estas dos leyes implican el ordenamiento jurídico francés en la protección de ciertos derechos colectivos reconocidos institucionalmente.

Asimismo, para las asociaciones no profesionales rige el artículo 2 del Código de Procedimientos Penales de 1958, que requiere la existencia de un interés actual y directo para la constitución en parte civil ${ }^{43}$.

Un tipo de asociaciones que revisten particular importancia son las de los consumidores, reguladas por la Ley Royer 1193 de 1973, ya que su protección da entrada a la tutela supraindividual como una especie de acción colectiva, quedando legitimadas ciertas asociaciones en aquellos casos en que exista una actividad ilícita dañina a los intereses del consumo (intereses difusos) $)^{44}$.

Otra de las manifestaciones de tutela de los interese difusos en Francia se pone en evidencia cuando las personas sufren un perjuicio a consecuencia de una ley penal, caso en el cual estas cuentan con la posibilidad de presentar su demanda por daños y perjuicios unida a la persecución penal del delito o infracción penal. Al respecto, el artículo 2 del Código Penal francés impone al demandante probar que ha sufrido personalmente un perjuicio en virtud de la conducta violatoria de la disposición del derecho criminal por parte del demandado ${ }^{45}$.

Luego de las iniciales expresiones de tutela de los derechos colectivos, el 1 de octubre de 2014 entró en vigor la Ley 2014-344 del 17 de marzo de $2014^{[46]}$, sobre Protección al Consumidor, donde se introduce la "acción de clase", o "acción de grupo", a efecto de que las asociaciones de consumidores aprobadas puedan interponer un recurso colectivo contra los operadores económicos.

Asimismo, el 24 de septiembre de 2014 se publicó el Decreto 2014-1081 ${ }^{[47]}$, el cual establece el procedimiento para la acción colectiva con fundamento en el Código Civil francés, a fin de que los consumidores cuenten con una tutela en contra de los operadores económicos.

De acuerdo con el artículo 2 de la citada Ley 2014-344, el tribunal competente para conocer del asunto en vía ordinaria será el tribunal superior (tribunal de

42 Cfr. Hernández Martínez, M. D. P. Mecanismos de tutela de los intereses difusos, cit., 133 .

43 Ibíd

44 Ibíd., 136.

45 Ibíd., 137.

46 Ley 2014-344 del 17 de marzo de 2014, sobre Protección al Consumidor.

47 Decreto 2014-1081. Diario Oficial de la República Francesa n. ${ }^{\circ} 223$ del 26 del mismo mes y año. 
grande instance) del lugar donde el demandado tenga su residencia principal; salvo en los casos en los que el demandado esté domiciliado en el extranjero o se desconozca su lugar de residencia, en cuyo caso el tribunal competente será el Tribunal Superior de París (Tribunal de grande instance de Paris). O sea que con esta regulación Francia se convirtió en el país europeo que ha concretado una regulación específica en materia de acciones colectivas.

De lo anterior se desprende el principio de legitimación activa, consistente en que las personas que sufren un perjuicio deben probar que han sufrido un menoscabo a sus intereses para presentar su demanda por daños.

\subsection{Latinoamérica}

\subsubsection{Brasil}

Por lo que se refiere a este sistema, nos remitiremos al análisis que realizó el destacado jurista brasileño Gregório Assagra de Almeida sobre el artículo 39 del Código Modelo de Procesos Colectivos ${ }^{48}$, con la participación del Instituto Iberoamericano de Derecho Procesal; pues, como hemos mencionado, dicho proyecto se basó esencialmente en el Código del Consumidor Brasileño ${ }^{49}$. El citado precepto establece que "Este Código será interpretado de forma abierta y flexible, compatible con la tutela colectiva de los intereses y derechos de que se trata" ${ }^{50}$. Esto significa que se deben incorporar todos los principios fundamentales de derecho procesal colectivo, los cuales se relacionan con la necesidad de flexibilización de la técnica procesal para garantizar la efectiva tutela de los derechos colectivos. Además, el referido autor menciona los siguientes principios procesales:

1. Principio del interés jurisdiccional en el conocimiento del mérito del proceso colectivo. "Con base en este principio, el Juez debe reflexionar los requisitos de admisibilidad procesal para enfrentar el mérito del proceso colectivo y legitimar la función social de la jurisdicción" 51.

2. Principio de la máxima prioridad de la tutela jurisdiccional colectiva. "Ese principio impone que se dé prioridad en su tramitación al derecho colectivo" 52 .

3. Principio de la presunción de la legitimidad "ad causam" activa por la afirmación del derecho colectivo tutelable. "[P]ara la tutela jurisdiccional

48 Cfr. Assagra de Almeida, G. Artículo 39. En Gidi, A. y Ferrer Mac-Gregor, E. (coords.), Código Modelo de Procesos, cit., 391-404.

49 Código del Consumidor brasileño.

50 GidI,A. Código de processo civil colectivo. Un modelo para países de direito escrito. En Revista de Processo, Revista de Tribunais, 111, 2003, 192-208, citado por Assagra DE AlmeIDA, G. Artículo 39, cit., 391.

51 Assagra de Almeida, G. Artículo 39, cit., 401.

52 Ibíd., 402. 
de los derechos difusos y colectivos no es necesaria la determinación y la individualización de sus titulares, sino que se torna suficiente la afirmación de derecho o interés colectivos para presumir la legitimidad activa" 53 .

4. Principio de la máxima amplitud de la tutela jurisdiccional colectiva. "A partir de él se impone la flexibilización de la técnica procesal para admitir todos los tipos de acciones, procedimientos, proveimientos jurisdiccionales y medidas necesarias y eficaces para la adecuada y eficiente tutela de los derechos e intereses difusos, colectivos e individuales homogéneos" ${ }^{54}$.

5. Principio del máximo beneficio de la tutela jurisdiccional colectiva. Mediante la tutela jurisdiccional colectiva se busca resolver, en un solo proceso, un gran conflicto social o innumerables conflictos interindividuales, evitándose, en este caso, la proliferación de acciones individuales y la concurrencia de situaciones conflictivas que puedan generar desequilibrio e inseguridad en la sociedad ${ }^{55}$.

6. Principio de la máxima efectividad del proceso colectivo. "Por fuerza de ese principio se debe alcanzar la verdad procesal en su grado máximo de probabilidad objetiva" 56 .

7. Principio de la no taxatividad de la acción colectiva. "Todos los derechos e intereses difusos o colectivos podrán ser objeto de acción colectiva" ${ }^{57}$.

8. Principio de la disponibilidad motivada y de la prohibición del abandono de la acción colectiva. "El abandono de la acción colectiva no es admisible, por tanto, no es compatible con el derecho procesal colectivo la extinción del proceso sin resolución del mérito con base en el abandono de la causa" ${ }^{58}$.

9. Principio de la obligatoriedad de la ejecución colectiva por el Ministerio Público. "Si el derecho difuso o colectivo ya está reconocido en título ejecutivo judicial o extrajudicial, su ejecución deberá ser ejecutada por el Ministerio Publico o por otro legitimado público" 59 .

10. Principio de la legitimidad activa concurrente o pluralista. "La legitimidad activa en el derecho procesal colectivo deberá ser siempre concurrente y pluralista, conforme al adoptado por el art. $3 .^{\circ}$ del Código Modelo" ${ }^{60}$.

11. Principio de la interpretación abierta y flexible de la causa de pedir y del pedido. "Los cuales podrán ser alterados en cualquier tiempo o grado de jurisdicción, pero desde que sea observado el contradictorio, que no exista mala fe y que no ocurra perjuicio injustificable para la parte" ${ }^{\text {" } 1}$. 


\subsubsection{México}

El 29 de julio de 2010 se publicó en el Diario Oficial de la Federación (DOF) la reforma al artículo 17 de la Constitución Política de los Estados Unidos Mexicanos (CPEUM) ${ }^{62}$, a través de la cual se contempla expresamente el compromiso de regular el tema de las acciones colectivas. Pero, fue solo el 30 de agosto de 2011 que se publicó en el Dof la reforma al Código Federal de Procedimientos Civiles (CFPC) y otros ordenamientos jurídicos sobre la instrumentación de las acciones colectivas ${ }^{63}$. Sin embargo, es de mencionar que el artículo 578 del citado código limita su procedencia a la defensa y protección de los derechos e intereses difusos en materia de consumo de bienes o servicios, públicos o privados, y medio ambiente.

En ese sentido, respecto a los principios interpretativos que pueden desprenderse de la legislación mexicana, Trejo Orduña señala que la facultad discrecional con que cuenta el juzgador no debe ser arbitraria, sino atender a los principios de legalidad y seguridad jurídica; asimismo, el juez deberá fundar y motivar el plazo que conceda a las partes, procurando que no sea muy prolongado, para el cumplimiento de la sentencia, y pierda su efectividad. Lo mismo acontece con los medios de apremio que, en su caso, deberá aplicar el juzgador para hacer cumplir la sentencia emitida en una acción colectiva ${ }^{64}$.

Siguiendo este orden de ideas, uno de los principios que rigen toda controversia judicial es el de las formalidades esenciales del procedimiento, entre las cuales se cuenta la notificación a las partes de las determinaciones asumidas en un proceso ${ }^{65}$. El artículo 608 del mismo ordenamiento establece que la sentencia deberá ser notificada a la colectividad o grupo de que se trate de manera personal, en los términos del segundo párrafo del artículo 591, el cual dispone que la notificación deber ser en forma personal al representante legal de la colectividad.

Por su parte, Sánchez López, en el análisis que realiza del artículo 583 del referido Código Federal Adjetivo Civil, señala que, para lograr una interpretación amplia y óptima del mencionado artículo, los principios que deben

62 Decreto por el que se adiciona un párrafo tercero y se recorre el orden de los párrafos subsecuentes del artículo 17 de la Constitución Política de los Estados Unidos Mexicanos (CPEUM). Diario Oficial de la Federación (DOF), 29 de julio de 2010.

63 Decreto por el que se reforman y adicionan el Código Federal de Procedimientos Civiles, el Código Civil Federal, la Ley Federal de Competencia Económica, la Ley Federal de Protección al Consumidor, la Ley Orgánica del Poder Judicial de la Federación, la Ley General del Equilibrio Ecológico y la Protección al Ambiente, y la Ley de Protección y Defensa al Usuario de Servicios Financieros. DOF, 30 de agosto de 2011.

64 Trejo Orduña, J. J. La sentencia y cosa juzgada en las acciones colectivas. En CASTILLO González, L. y Murillo Morales, J. (coords.), Acciones colectivas, cit.

65 Ibíd. 
observarse en las acciones colectivas, conforme al citado Código Modelo de Procesos Colectivos para Iberoamérica, son los siguientes ${ }^{66}$ :

1. El de la máxima prioridad de la tutela jurisdiccional colectiva, que impone que se dé primacía a la tramitación del proceso colectivo;

2. Interpretación abierta y flexible de la causa de pedir y del pedido.

3. Máxima efectividad del proceso colectivo, lo que implica que para conseguir ese objetivo se deberá procurar, de oficio, el desahogo de todas las pruebas pertinentes y relevantes, para que la tutela jurisdiccional se agote.

Esos principios deben articularse con las normas reguladoras de la prueba en las acciones colectivas, que no tienen que ver precisamente con los requisitos formales y las etapas que se deben cumplir con la intervención de las partes, la cual es más amplia que en otros ordenamientos, sino con el ejercicio de los poderes probatorios atribuidos al juez por el legislador, básicamente en los artículos 598 y 599 del CFPC $^{67}$.

A lo anterior agregamos el principio pro persona, pues, tal como lo manifiestan Rivera Pedroza y Gómez Magaña, este principio obliga a los jueces a hacer una interpretación del derecho tal que maximice el disfrute de los derechos humanos por parte de sus titulares ${ }^{68}$.

Bajo ese tenor, corresponderá a los tribunales federales analizar las peticiones de fondo que se hagan al respecto, en relación con las acciones colectivas, y cuidar que los principios para las acciones y procedimientos colectivos sean compatibles con la finalidad de estos y adaptarlos a las peculiaridades del sistema procesal mexicano, al margen de las herramientas con las que se cuente en las legislaciones secundarias.

\subsubsection{Colombia}

Londoño Toro manifiesta que "[u]na de las principales preocupaciones en la defensa de los derechos humanos, y entre ellos los de tercera generación, es el de acceso [sic] a la justicia" ${ }^{69}$, y agrega que "[1]os derechos colectivos exigen mecanismos supraindividuales para la defensa de la colectividad y de los grupos". ${ }^{70}$ Mientras que la Constitución colombiana ${ }^{71}$, en su artículo 88 , dispone que las acciones populares incluyen las acciones colectivas, con

66 SÁNCHEz LóPEZ, A. La sentencia y cosa juzgada en las acciones colectivas. En CASTILLO González, L. y Murillo Morales, J. (coords.), Acciones colectivas, cit., 272.

67 Ibíd., 273.

68 Rivera Pedroza, A. y Gómez Magaña, E. Acciones colectivas. Incidencia de las organizaciones de la sociedad civil en la reivindicación de derechos. México: Instituto Mexicano para el Desarrollo Social, Cultural, Artístico, Tecnológico, Educativo y Ecológico, 2012, 78.

69 LONDOÑO TORO, B. Las acciones colectivas en defensa de los derechos de tercera generación. En Estudios Socio-Jurídicos, Universidad del Rosario (Argentina). Vol. 1, n. ${ }^{\circ}$ 2, 2015, 1.

70 Ibíd.

71 Constitución de Colombia de 1991. 
lo cual cualquier persona puede defender los intereses que le son comunes a toda una colectividad ante los tribunales, lo que motiva la defensa de esos intereses.

Es de mencionar que, en el caso de Colombia, tanto el ordenamiento civil como el administrativo regulan el procedimiento de las acciones populares atendiendo al origen del interés protegido; esto es, cuando la vulneración de los derechos e intereses colectivos provenga de la actividad de una entidad pública, podrá demandarse su protección mediante la instancia administrativa; en cambio, el Código General del Proceso dispone que los jueces civiles conocerán de las acciones populares y de grupo no atribuidas a la jurisdicción de lo contencioso administrativo, como es el caso de los derechos de los consumidores.

Sobre los principios que rigen el mecanismo de defensa de los intereses colectivos y difusos en Colombia, Camargo ${ }^{72}$ asevera que, conforme al artículo 5 de la Ley 472 de $1998^{[73]}$, los trámites de las acciones populares se desarrollan con fundamento en los principios constitucionales, y especialmente en los de prevalencia del derecho sustancial, publicidad, economía, celeridad y eficacia; asimismo, se aplicarán los principios generales del Código de Procedimiento Civil, cuando estos no se contrapongan a la naturaleza de dichas acciones.

Enseguida, el mencionado autor agrega que, en virtud de que la citada Ley 472 no define los principios rectores de la acción popular, hay que acudir entonces a los principios de administración de justicia, contenidos en la Ley 270 de $1996^{[74]}$, Estatutaria de la Administración de Justicia, así como también a los principios contenidos en el Código de Procedimiento Civil, habida cuenta de que en el referido artículo 5 se indica que "se aplicarán también los principios generales del Código de Procedimiento Civil, cuando estos no se contrapongan a la naturaleza de dichas acciones"75.

Importa aclarar que el Código de Procedimiento Civil y el Código Contencioso Administrativo, que fueron invocados por el autor citado, actualmente se encuentran abrogados; de manera que los ordenamientos relativos que hoy están vigentes son el Código General del Proceso ${ }^{76}$ y el Código de Procedimiento Administrativo y de lo Contencioso Administrativo (CPACA) ${ }^{77}$,

72 Camargo, P. P. Las acciones populares y de grupo. Guía práctica de la Ley 472 de 1998. 6. a ed. Bogotá: Leyer, 2009, 68.

73 Ley 472 de 1998, por el cual se desarrolla el artículo 88 de la Constitución Política de Colombia en relación con el ejercicio de las acciones populares y de grupo y se dictan otras disposiciones.

74 Ley 270 de 1996, Estatutaria de la Administración de Justicia.

75 CAmargo, P. P. Las acciones populares y de grupo, cit., 168.

76 Código General del Proceso, 2012, Colombia.

77 Código de Procedimiento Administrativo y Contencioso Administrativo, 2011, Colombia. 
de los cuales también se desprenden los principios que han sido analizados por el citado maestro.

En ese sentido, para efectos de analizar el objeto de estudio en este país, se tomarán como referencia los principios que identifica el jurista Pedro Pablo $\mathrm{Camargo}^{78}$; no obstante, la información se complementará haciendo referencia a aquellos preceptos legales que sobre la materia consagran los mencionados ordenamientos vigentes; así pues, los principios que se advierten son:

a) Prevalencia del derecho sustancial sobre el adjetivo. Este principio emana del artículo 228 de la Constitución Política. La administración de justicia es función pública, sus decisiones son independientes. Las actuaciones serán públicas y permanentes con las excepciones que establezca la ley, y en ellas prevalecerá el derecho sustancial.

Mientras que el artículo 17 de la precitada Ley 472 señala que, en el desarrollo del principio de prevalencia del derecho sustancial sobre el procesal, el juez competente que reciba la acción popular tendrá la facultad de tomar las medidas cautelares necesarias para impedir perjuicios irremediables e irreparables o suspender los hechos generadores de la amenaza a los principios e intereses colectivos. Igualmente, dispone el artículo 25 de la ley que nos ocupa que, antes de ser notificada la demanda, en cualquier estado del proceso, podrá el juez, de oficio o a petición de parte, decretar, debidamente motivadas, las medidas previas que estime pertinentes para prevenir un daño inminente o para hacer cesar el que se hubiere causado.

b) Publicidad. El juez de conocimiento dará a conocer sus decisiones mediante las comunicaciones, notificaciones o publicaciones que ordena la Ley 472 de referencia. Todo proceso de acción popular es público y al mismo tienen acceso no solo las partes sino el público en general que quiera enterarse.

c) Economía procesal. Al respecto, el numeral 1 del artículo 42 del Código General del Proceso impone como deberes del juez: dirigir el proceso, velar por su rápida solución, presidir las audiencias, adoptar las medidas conducentes para impedir la paralización y dilación del proceso y procurar la mayor economía procesal.

Asimismo, el numeral 12 del CPACA dispone que, en virtud del principio de economía, las autoridades deberán proceder con austeridad y eficiencia, optimizar el uso del tiempo y de los demás recursos, procurando el más alto nivel de calidad en sus actuaciones y la protección de los derechos de las personas.

d) Celeridad. Sobre el particular, el numeral 13 del artículo 3 del CPACA manifiesta que, en virtud del principio de celeridad, las autoridades impulsarán oficiosamente los procedimientos, e incentivarán el uso de las tecnologías de la información y las comunicaciones, a efectos de que los procedimientos 
se adelanten con diligencia, dentro de los términos legales y sin dilaciones injustificadas.

Por su parte, el artículo 84 de la citada Ley 472 precisa que la inobservancia de los términos procesales establecidos en esta ley será sancionable al juez con destitución de cargo.

e) Eficacia. Al respecto, el artículo 3 del Código de Procedimiento Administrativo y de lo Contencioso Administrativo en estudio dispone que las autoridades buscarán que los procedimientos logren su finalidad y, para el efecto, removerán de oficio los obstáculos puramente formales, evitarán decisiones inhibitorias, dilaciones o retardos y sanearán, de acuerdo con este Código, las irregularidades procedimentales que se presenten, en procura de la efectividad del derecho material objeto de la actuación administrativa.

Asimismo, el artículo 5 de la citada Ley 472 establece claramente que, promovida la acción, es obligación del juez impulsarla oficiosamente y producir decisión de mérito, so pena de incurrir en falta disciplinaria, sancionable con destitución. Esta última prerrogativa empata con el denominado principio de prohibición del abandono de la acción colectiva regulado en la legislación brasileña, por lo que, desde este momento podemos advertir coincidencias en los parámetros del proceso de las acciones colectivas.

\subsubsection{Similitudes y diferencias}

Las similitudes que puedan encontrarse en los contenidos normativos y la doctrina de cada país, lo cual, al constituir un sistema jurídico único, va a depender, por supuesto, de diversos factores, como pueden ser la familia tradicional jurídica a la que pertenece cada país, su desarrollo, su cultura, su historia, sus tradiciones, su organización económica, social y política, su evolución sociológica, etcétera.

En el caso de los tres países europeos elegidos para este estudio, es decir, Alemania, España y Francia, debemos decir que tienen varias características en común. En primer lugar, forman parte de la familia del civil law y, en segundo lugar, forman parte, además, de los 28 países que integran actualmente la Unión Europea ${ }^{79}$; por consiguiente, están vinculados con el derecho internacional y regional europeo de los derechos humanos, con base, entre otros tratados internacionales, en la Carta de las Naciones Unidas vigente desde el 24 de octubre de $1945^{[80]}$, en la Declaración Universal de Derechos Humanos

79 Miembros actuales de la Unión Europea. Disponible en: http://www.internationaloliveoil.org/estaticos/view/74-miembros-actuales-de-la-union-europea/?lang=es_ES

80 Carta de las Naciones Unidas vigente desde el 24 de octubre de 1945. Disponible en: https://www.un.org/es/charter-united-nations/ 
proclamada el 10 de diciembre de $1948^{[81]}$, en el Convenio Europeo para la Protección de los Derechos Humanos y Libertades Fundamentales del 4 de noviembre de $1950^{[82]}$ y en la Carta de los Derechos Fundamentales, proclamada por el Parlamento Europeo, el Consejo Europeo y la Comisión Europea el 7 de diciembre de $2000^{[83]}$, la cual en su artículo 28 se refiere al derecho de los trabajadores y empresarios, o de sus organizaciones respectivas, en caso de conflicto, de acudir a las acciones colectivas para la defensa de sus intereses. Otra característica, a la que se refiere López Daza, es que ninguno de dichos países ha tenido "una tradición de exigibilidad a través de la vía judicial" sino que, más bien, agrega este autor, su atención ha sido un asunto más de política pública, lo que ha permitido la conservación de "verdaderos estados de bienestar (welfare state, État providence) en el siglo xxI" 85 . Pero esto no es todo: Alemania (art. 20 constitucional) ${ }^{86}$ y España (art. 1. ${ }^{\circ}$ constitucional) ${ }^{87}$ están organizados constitucionalmente bajo un Estado social y democrático de derecho, o sea que desde el código supremo se encuentran comprometidos con la protección de los derechos sociales. Francia sigue esa misma línea, pues desde la Constitución de 1946 establece su compromiso con los derechos económicos y sociales (art. 2..$^{\circ}$ ), situación que ratifica desde el preámbulo de la Constitución de 1958 actualmente en vigor, así como en su artículo $1 .^{\circ}$, el cual establece que se organiza bajo una "República indivisible, laica, democrática y social" $"$. Algo que deseamos destacar igualmente es que la naturaleza de los derechos sociales es muy diferente a la de los derechos individuales. Sin embargo, por lo que se refiere a los derechos procesales de las acciones colectivas, y, sobre todo, a los principios procesales, la línea que los separa es muy delgada, pues, como quiera que sea, en ambos casos, según lo hemos venido exponiendo, estamos hablando, actualmente, de que su fundamento lo encontramos tanto en las leyes constitucionales y supremas de cada país como en el derecho convencional.

Lo anterior coincide con lo que el propio Alexy sostiene sobre los principios en el estudio que realiza del derecho alemán, al señalar que aquellos pueden referirse, igualmente, a derechos y bienes colectivos como la salud pública, el abastecimiento energético, el derecho a la alimentación, la lucha

81 Declaración Universal de los Derechos Humanos. Disponible en: https://www.un.org/ es/universal-declaration-human-rights/

82 Convenio Europeo para la Protección de los Derechos Humanos y Libertades Fundamentales del 4 de noviembre de 1950.

83 Carta de los Derechos Fundamentales de la Unión Europea, proclamada el 7 de diciembre de 2000. Diario Oficial de las Comunidades Europeas. Véanse, específicamente, sus artículos 34 a 39 .

84 López Daza, G. A. Los derechos sociales en Alemania, España, Italia y Francia, cit., 12.

85 Ibíd., 13.

86 Ley Fundamental de la República Federal de Alemania, cit.

87 Constitución española de 1978, cit.

88 Constitución francesa del 4 de octubre de 1958. 
por el desempleo, la estructura de las fuerzas armadas, la seguridad del país, la protección del orden democrático, la protección del medio ambiente, etc. Por otra parte, sigue exponiendo, "el Tribunal Constitucional alemán concibe a las normas iusfundamentales como principios" ${ }^{\circ 9}$. O sea que, en el derecho alemán, tanto los derechos individuales como los derechos de los bienes colectivos están contemplados como principios. Pero también, "[e]l hecho de que, a través de las disposiciones iusfundamentales, se estatuyan dos tipos de normas, es decir, las reglas y los principios, fundamenta el carácter doble de las disposiciones iusfundamentales" ${ }^{90}$. De lo anterior se desprende que tanto los derechos individuales como los derechos de los bienes colectivos están contemplados como principios y como derechos fundamentales, por consiguiente, son normas de rango constitucional, o, lo que es lo mismo, normas de máxima jerarquía ${ }^{11}$.

Por lo que se refiere a los tres países latinoamericanos, Brasil, México y Colombia, la evolución de las acciones colectivas, igual que la de sus principios procesales, es muy diferente de la vía tutelar empleada por los europeos (a través de políticas públicas), pues aquí vamos a encontrar una vasta experiencia en el tema de su tutela a través de las garantías judiciales. En el caso, destaca Brasil, que cuenta con una amplia experiencia en la protección de los derechos sociales y en la adopción de sus principios procesales, a partir del Código modelo de acciones colectivas. Sin embargo, México fue el primer país en el mundo que elevó a rango constitucional los derechos sociales, esto en la Constitución del 5 de febrero 1917; lo siguieron Rusia, en 1918, con el triunfo de la Revolución Bolchevique, y la Constitución de Weimar de 1919. Aunque, hay que reconocerlo, México se tardó en instrumentar su tutela hasta las ya mencionadas reformas constitucionales de 2010 y 2011, o sea, cerca de cien años. Por su parte, Colombia ha logrado establecer, de la misma manera, desde el nivel constitucional, su propio modelo de las acciones colectivas con base en las acciones populares; asimismo, en su legislación interna, este tipo de acciones se encuentran reguladas tanto en el ámbito civil como en el administrativo. Por lo que se refiere a los principios procesales de los procesos colectivos, en cada país, como hemos visto, no los podemos separar, los unos de los otros. Pero, tampoco podemos decir que estemos hablando del mismo modelo, como lo señala infra el doctrinario Pérez Luño. Esto es, cada país latinoamericano de los tres abordados tiene sus principios procesales, producto igualmente de su propia evolución histórica.

Sin embargo, es posible ubicar la existencia uniforme de ciertos principios procesales de las acciones colectivas que imperan en estos países, como son: el principio de legitimación activa, el principio de máxima amplitud

89 Alexy, R. Teoría de los derechos fundamentales, cit., 115.

90 Ibíd., 135.

91 Ibíd., 223. 
de la tutela jurisdiccional colectiva, el principio de máxima efectividad del proceso, la legitimación plural, la cosa juzgada, la ejecución de sentencia, el derecho de defensa, el principio de audiencia, el debido proceso. Incluso de algunos principios, aunque tengan denominación diferente en cada cuerpo legislativo, se puede decir que el sentido es el mismo, como en el caso del principio de celeridad, eficacia y economía procesal.

En contraste con lo anterior, también es posible advertir principios que son exclusivos de cada sistema jurídico; tal es el caso del principio de prohibición del abandono de la acción colectiva y del principio de ejecución colectiva por el Ministerio Público que contempla la legislación brasileña; del principio de prevalencia del derecho sustancial sobre el adjetivo en el caso de Colombia; o bien, del principio de indemnización real del daño que consagra la normatividad española.

Estos principios son directrices emanadas de cada sistema jurídico y que no pueden ser desconocidas, pues de lo contrario causarían un menoscabo tanto en el proceso como en la defensa de los intereses en conflicto. Así pues, el proceso colectivo debe verse guiado por dichos principios para obtener un mejor desarrollo en el proceso.

Por otra parte, cabe destacar un aspecto que también identifica a los seis países en estudio, derivado de la influencia del derecho internacional de los derechos humanos, debido a lo cual, cada vez más, los principios procesales de las acciones colectivas se han ido acercando; nos referimos al Pacto Internacional de los Derechos Económicos, Sociales y Culturales (PIDESC), adoptado y abierto a la firma, ratificación y adhesión por la Asamblea General de la Organización de las Naciones Unidas (ONU) en su Resolución 2200 A (xxI), el cual entró en vigor el 16 de diciembre de 1966, que implica la obligación de cada Estado-miembro de cumplir y, sobre todo, garantizar esos derechos ${ }^{92}$, máxime con la entrada en vigor del Protocolo Facultativo del PIDESC, vigente en España a partir del 5 de mayo de $2013^{[93]}$, lo que constituye un gran avance en términos de justiciabilidad de esos derechos a través de la presentación de comunicaciones individuales, de comunicaciones entre Estados y de investigación ante violaciones graves o sistemáticas de esta gama

92 Cfr. González Monguí, P. E. (Coord.). Derechos económicos, sociales y culturales. Bogotá: Kimpres, 2009; véase, además, el PIDESC. Disponible en: https://www.ohchr.org/SP/ ProfessionalInterest/Pages/CESCR.aspx; Estado de ratificación del Pacto Internacional sobre Derechos Económicos, Sociales y Culturales en 2013. Disponible en: https://www.ohchr.org/ SP/Issues/ESCR/Pages/ESCRIndex.aspx

93 Protocolo Facultativo del PIDESC. Disponible en: https://www.ohchr.org/SP/ProfessionaIInterest/Pages/OPCCPR1 aspx; véase, también, RiQuelme CORTADO, R. Entrada en vigor, general y para España del Protocolo Facultativo del Pacto Internacional de Derechos Económicos, Sociales y Culturales. En Anuario de Acción Humanitaria y Derechos Humanos, Universidad de Deusto. N. . 11, 2013, 75-107. 
de derechos para denunciar ante una instancia internacional la violación de dichos derechos considerados de segunda generación ${ }^{94}$.

La Convención Americana sobre Derechos Humanos del 22 de noviembre de $1969^{[95]}$ ha sido firmada por los tres países latinoamericanos considerados en nuestro estudio ${ }^{96}$. Estos han aceptado, asimismo, la competencia jurisdiccional de la Corte Interamericana de Derechos Humanos (Corte IDH). Además, han aceptado el Protocolo Adicional a la Convención Americana sobre Derechos Humanos en materia de Derechos Económicos, Sociales y Culturales, conocido también como "Protocolo de San Salvador"97.

Otro elemento que, igualmente, ha permitido este acercamiento es la relación, cada vez más estrecha, entre los derechos individuales y los derechos colectivos-sociales. Me refiero, aquí, a principios procesales como los de interpretación conforme, pro homine, seguridad jurídica y debido proceso, que permean todos los ámbitos de los derechos en todos los países de Occidente y de Latinoamérica, sin hacer diferencias. Esto es, estamos hablando de principios procesales que tienen una relación directa con los derechos fundamentales, con características universales e indivisibles, no importando si son derechos individuales o colectivos, pues al final del camino podemos decir que ambos son derechos humanos que, en términos de la teoría del ius naturale, los seres humanos tienen, solo por el hecho de ser personas. Por lo anterior, podemos decir que existen más similitudes que diferencias entre los principios procesales de los seis países en estudio y, por consiguiente, están protegidos por el derecho constitucional y convencional.

Desde luego, esto de ninguna manera significa, como también lo hemos visto, que el desarrollo de los principios procesales en los países en estudio haya tenido lugar de manera idéntica, semejante y homogénea. Al contrario, cada país tiene su propia evolución, pues, como nos dice Pérez Luño, "las generaciones no entrañan un proceso cronológico o lineal", y agrega que el catálogo de las libertades no puede ser una obra cerrada y acabada. Los derechos reflejan un proyecto emancipatorio que se concreta de modo diferente a lo largo de la historia" ${ }^{98}$. En síntesis, esto explica que la adopción en el tiempo de los principios procesales, en cada uno de esos países, sea

94 Ibíd., 75, 78.

95 Convención Americana sobre Derechos Humanos del 22 de noviembre de 1869. Disponible en: https://www.oas.org/dil/esp/tratados_B-32_Convencion_Americana_sobre_Derechos_Humanos.pdf

96 Brasil ratificó su adhesión el 7 de septiembre de 1992, México lo hizo el 3 de febrero de 1981 y Colombia el 28 de mayo de 1973. Cfr. firmas y ratificaciones en: http://www.oas.org/ dil/esp/tratados_B-32_Convencion_Americana_sobre_Derechos_Humanos_firmas.htm

97 Protocolo Adicional a la Convención Americana sobre Derechos Humanos en materia de Derechos Económicos, Sociales y Culturales, conocido también como "Protocolo de San Salvador". Disponible en: https://www.oas.org/juridico/spanish/firmas/a-52.html

98 Cfr. Rodríguez Palop, M. E. Antonio Enrique Pérez Luño: la tercera generación de derechos humanos. Navarra: Aranzadi, 2006, 278. 
diferente; tan diferente como su propia evolución histórica; tal es el caso de Alemania y España, que atravesaron por dos dictaduras militares (nazismo y fascismo), mientras que Francia, ni aun siendo la cuna del Estado de derecho liberal, logró la estabilización política sino hasta muchos años después. Lo mismo sucedió en cada uno de ellos con el origen y desarrollo de la legislación secundaria sobre las acciones colectivas y sus principios procesales.

\section{A MANERA DE CONCLUSIONES}

En este contexto, podemos decir, siguiendo a Robert Alexy, que los derechos iusfundamentales contenidos en las constituciones de cada país en estudio, también constituyen el núcleo central de los principios procesales de las acciones colectivas, pues hay que tener siempre presente que, si hablamos de vulneración de los derechos colectivos, en muchas ocasiones también hablamos de violación a los derechos públicos subjetivos; en efecto, en ambos casos, siempre estaremos hablando de violación de derechos humanos, en virtud de que entre ellos hay una línea muy delgada.

Efectivamente, como pudimos observar en la doctrina y la legislación de los seis países de referencia, así como en el derecho convencional universal, europeo y del sistema interamericano, tanto los derechos individuales como los derechos económicos, sociales y culturales descansan, como lo señalamos supra (3), en el principio de la dignidad de las personas, que sostiene todo el edificio de los derechos humanos; máxime que, conforme a la filosofía del derecho natural, estos derechos les pertenecen a los individuos simplemente por el hecho de ser personas.

En ese mismo orden de ideas, y conforme al derecho internacional de los derechos humanos, basado en los tratados internacionales sobre la materia que citamos, esos derechos descansan también en los siguientes principios: son indivisibles, interdependientes, progresivos, imprescriptibles, inalienables, universales; sin embargo, todo esto no es suficiente para sostener que los principios procesales de los mencionados derechos colectivos son homogéneos, pues la organización de cada país es diferente en cuanto a su normatividad interna.

Tampoco existe homogeneidad entre los principios procesales para la tutela de las acciones colectivas, por parte de los sistemas jurídicos de los seis países mencionados; al contrario, aun cuando entre ellos se observan grandes similitudes, también existen marcadas diferencias, pues su origen, evolución, desarrollo y estructura social, económica, jurídica, cultural, histórica son muy diferentes. 


\section{REFERENCIAS}

Alexy, R. Teoría de los derechos fundamentales. Madrid: Centro de Estudios Constitucionales, 1993.

Armenta-Deu, T. Acciones colectivas: reconocimiento, cosa juzgada y ejecución, España: Marcial Pons, 2013.

Armienta Calderón, G. M. Teoría general del proceso. Principios, instituciones y categorías procesales. México: Porrúa, 2003.

Assagra de Almeida, G. Artículo 39. En Gidi, A. y Ferrer Mac-Gregor, E. (coords.), Código Modelo de Procesos Colectivos. Un diálogo iberoamericano. Comentarios artículo por artículo. México: Porrúa-unam, 2008.

Ávila, H. Teoría de los principios. Laura Criado Sánchez (trad.). España: Marcial Pons, 2011.

Barajas Villa, M. La construcción jurisprudencial de la tutela efectiva de los derechos humanos, a través del método del derecho comparado: clave del éxito de las acciones colectivas en México. En Castillo González, L. y Murillo Morales, J. (coords.), Acciones colectivas. Reflexiones desde la judicatura. México: Instituto Judicatura Federal, Escuela Judicial, 2013.

Borthwick, A. E. Principios procesales. Argentina: mave, 2003.

Camargo, P. P. Las acciones populares y de grupo. Guía práctica de la Ley 472 de 1998. 6. '. ed., Bogotá: Leyer, 2009.

Castillo González, L. y Murillo Morales, J. (Coords.). Acciones colectivas. Reflexiones desde la judicatura. México: Instituto Judicatura Federal, Escuela Judicial, 2013.

Corominas BAch, S. La legitimación activa en las acciones colectivas. Tesis doctoral, Universidad de Girona, 2015.

Fauth, G. y Villavicencio Calzadilla, M. P. Una reflexión sobre los "nuevos" derechos. Perspectivas y desafíos en el siglo XXI. En Revista de la Facultad de Derecho, PUCP. N. ${ }^{\circ} 70,2013$.

García Pino, G. Gustavo Zagrebelsky: en busca de la razón en el derecho. En Revista de Derecho Público. Vol. 80, 1. ${ }^{\text {er }}$ semestre, 2014.

GIDI, A. Las acciones colectivas y la tutela de los derechos difusos, colectivos e individuales en Brasil. Un modelo para países de derecho civil. Lucio Cabrera Acevedo (trad.). México: UnAm-IIJ, 2004.

Gidi, A. y Ferrer Mac-Gregor, E. (Coords.). Código Modelo de Procesos Colectivos. Un diálogo iberoamericano. Comentarios artículo por artículo. México: Porrúa-unam, 2008.

Gómez Rodríguez, J. M. La contribución de las acciones colectivas al desarrollo regional desde la perspectiva del derecho social. En Cuestiones Constitucionales. Revista Mexicana de Derecho Constitucional. N. ${ }^{\circ}$ 30, 2014. 
González Monguí, P. E. (Coord.). Derechos económicos, sociales y culturales. Bogotá: Kimpres, 2009.

Hernández Martínez, M. D. P. Mecanismos de tutela de los intereses difusos y colectivos. México: unam, 1997.

Koch, H. Procesos colectivos. La tutela de los derechos difusos, colectivos e individuales en una perspectiva comparada. En Gidi, A. y Ferrer MaC-Gregor, E. (coords.), Procesos colectivos. La tutela de los derechos difusos, colectivos e individuales en una perspectiva comparada. 2. ed. México: Porrúa, 2004.

Londoño Toro, B. Las acciones colectivas en defensa de los derechos de tercera generación. En Estudios Socio-Jurídicos, Universidad del Rosario (Argentina). Vol. 1, n. ${ }^{\circ}$ 2, 2015.

López Daza, G. A. Los derechos sociales en Alemania, España, Italia y Francia. En Criterio Jurídico, Santiago de Cali. Vol. 12, n. ${ }^{\circ}$ 1, 2012.

López Oliva, J. O. La Constitución de Weimar y los derechos sociales. La influencia en el contexto constitucional y legal colombiano a la luz de los derechos sociales asistenciales a la seguridad social en salud. En Novum Jus. Vol. 4, n. ${ }^{\circ}$ 1, 2010.

Riquelme Cortado, R. Entrada en vigor, general y para España del Protocolo Facultativo del Pacto Internacional de Derechos Económicos, Sociales y Culturales. En Anuario de Acción Humanitaria y Derechos Humanos, Universidad de Deusto. N. . 11, 2013, 75-107.

Rivera Pedroza, A. y Gómez Magaña, E. Acciones colectivas. Incidencia de las organizaciones de la sociedad civil en la reivindicación de derechos. México: Instituto Mexicano para el Desarrollo Social, Cultural, Artístico, Tecnológico, Educativo y Ecológico, 2012.

Rodríguez Palop, M. E. Antonio Enrique Pérez Luño: la tercera generación de derechos humanos. Navarra: Aranzadi, 2006.

Rosales SÁnchez, J. J. Introducción a las acciones colectivas. En Castillo González, L. y Murillo Morales, J. (coords.), Acciones colectivas. Reflexiones desde la judicatura. México: Instituto de la Judicatura Federal, Escuela Judicial, 2013.

Sánchez López, A. La sentencia y cosa juzgada en las acciones colectivas. En Castillo González, L. y Murillo Morales, J. (coords.), Acciones colectivas. Reflexiones desde la judicatura. México: Instituto de la Judicatura Federal, Escuela Judicial, 2013.

Silvera de Pauli, M. Algunas peculiaridades del derecho al medio ambiente en la Teoría de los derechos humanos. Tesis, Universidad de Burgos, 2014.

SuÁrez Romero, M. A. Ley, principios jurídicos y derechos fundamentales en el actuar de los jueces y legisladores. Una propuesta positivista ante la templanza del constitucionalismo. En Derechos y Libertades, UnAm. Época II, n. ${ }^{\circ}$ 36, 2017.

Trejo Orduña, J. J. La sentencia y cosa juzgada en las acciones colectivas. En Castillo González, L. y Murillo Morales, J. (coords.), Acciones colectivas. Reflexiones desde la judicatura. México: Instituto Judicatura Federal, Escuela Judicial, 2013. 
VÁzQuez Sotelo, J. L. Los principios del proceso penal: legalidad, oportunidad y condena pactada. En Picò I Junoy, J. (coord.), Principios y garantías procesales. España: Bosch, 2013. 